\title{
Analisis Komponen Saluran Udara Tegangan Menengah (SUTM) 20 KV di Penyulang Merbau - Jambi
}

\author{
Rozlinda Dewi \\ Jurusan Teknik Listrik, Fakultas Teknik, Universitas Batanghari \\ Corersponding author: rozlinda.dewi@unbari.ac.id
}

\begin{abstract}
Abstrak. Perencanaan jaringan distribusi tidak lepas dari bagaimana sistem distribusi dibangun. Mulai dari perencanaan (konstruksi berikut komponen) hingga implementasi di lapangan, sangat menentukan kualitas dan keandalan sistem dapat terpenuhi. Penelitian ini menganalisis tentang implementasi komponen Saluran Udara Tegangan Menengah (SUTM) 20 kV lokasi Penyulang Merbau di Daerah Ma.Tembesi Kab.Batanghari-Jambi, apakah sesuai dengan standard yang digunakan oleh PLN (SPLN). Salah satunya adalah bagaimana menentukan jumlah komponen yang digunakan dalam proyek SUTM. Metoda penelitian yang digunakan adalah metode observasi dan pengukuran di lapangan. Metode observasi menggunakan teori standar yang baku sesuai Buku Standar Perusahaan Umum Listrik Negara (S-PLN). Hasil penelitian menyimpulkan bahwa pemakaian komponen di lapangan untuk pemakaian kabel penghantar AAAC sepanjang $11.025 \mathrm{~m}$ hampir mendekati standar, selisih hanya berkisar 7,2\% (+). Sedangkan pemakaian tiang walaupun jumlahnya sama 70 bh meliputi jenis tiang beton $12 \mathrm{~m} 200$ daN sebanyak 69 bh, tiang 9m 100 daN 13 bh, namun ada perbedaan jumlah dalam penggunaan tiang $12 \mathrm{~m}$ dan $9 \mathrm{~m}$ antara nilai hitung dan realisasi. Pemakaian tiang dengan panjang tertentu bagi pelaksana proyek seharusnya mereferensi Standar PLN walaupun beban kerja tiang masih terpenuhi (200 daN). Dengan selalu diadakannya evaluasi di setiap proyek maka data ini dapat digunakan sebagai masukan bagi pemilik maupun pelaksana proyek, agar kualitas dan keandalan sistem dapat terpenuhi
\end{abstract}

Kata kunci: Perencanaan, Jaringan distribusi, Komponen SUTM

\begin{abstract}
Distribution network planning is not loose from how the distribution system is built. From planning (the construction of the following components) to implementation in the field, determining the quality and reliability of the system can be fulfilled. This research analyzes about the implementation of medium-voltage air duct components (SUTM) $20 \mathrm{kV}$ rework location Merbau in the area Ma. Tembesi Kab. Batanghari-Jambi, is in accordance with the standard used by PLN (S-PLN). One is how to determine the number of components used in a SUTM project. The research method used is the observation and measurement methods in the field. The observation method uses standardized standard theory according to the standard Book of State electricity General Company (S-PLN). The results concluded that the use of components in the field for the use of an AAAC cable conductor for $11,025 \mathrm{M}$ is almost close to the standard, the difference only ranges from $7.2 \%(+)$. While the use of Poles although the same number of $70 \mathrm{BH}$ covers a type of concrete pole $12 \mathrm{~m} 200$ And as many as $69 \mathrm{BH}$, pole $9 \mathrm{~m} 100$ And 13 PCs, but there is a difference in the amount of the use of Poles $12 \mathrm{~m}$ and $9 \mathrm{~m}$ between the calculated and realization values The use of poles of certain lengths for project executor should reference the PLN standard even though the workload is still being fulfilled (200 And). With always being evaluated in each project, this data can be used as input for the project owner or executor, so that the quality and reliability of the system can be fulfilled
\end{abstract}

Keywords: planning, distribution network, SUTM component

\section{PENDAHULUAN}

Permintaan energi listrik yang terus meningkat, membutuhkan kemampuan penyaluran dan pendistribusian yang semakin efektif dan efisien agar energi tersebut sampai ke pengguna secara efektif dan efisien. Pendistribusian ini hendaklah memenuhi persyaratan sesuai dengan standar yang dikeluarkan oleh kementrian ESDM dan PT.PLN selaku Perusahaan Negara yang mengelola bidang kelistrikan.

Sistim distribusi itu sendiri terbag 2 (dua ) yaitu :

a. Sistim Distribusi Tegangan Menengah (JTM $20 \mathrm{KV}$ ), mempunyai tegangan kerja di atas $1 \mathrm{kv}$ dan setinggitingginya $35 \mathrm{kv}$

b. Sistim Distribusi Tegangan Rendah (JTR 380/220 V) mempunyai tegangan kerja setinggi-tingginya $1 \mathrm{kv}$.

Distribusi tenaga listrik ke pengguna tenaga listrik dengan penggunaan sistem Jaringan Tegangan Menengah (JTM) $20 \mathrm{kV}$ sebagai jaringan utama adalah upaya untuk menghindarkan rugi-rugi penyaluran (losses) dengan kwalitas persyaratan tegangan yang harus dipenuhi

Penelitian yang dilakukan Arfita Yuana Dewi Rachman, fauzan, Perencanaan Saluran Udara Tegangan Menengah (SUTM) $20 \mathrm{KV}$ Pada Komplek Perkebunan AMp (Agra Masang Perkasa) [1], berkaitan dengan penentuan kuat hantar arus pada ukuran kawat penampang dan jenis penghantar yang dipilih, menjadi dasar penelitian ini tentang penentuan jenis penghantar Penghantar (bahan, Panjang dan diameter).

Selain itu penelitian Andang Purnomo Putro, Kartono, ST. MT, Perluasan Jaringan Tegangan Menengah Tiga Phasa Di PT. Saniharto, Semarang [2] juga melengkapi tentang pilihan jenis penghantar SUTM adalah Penghantar Telanjang yang ditopang dengan isolator pada tiang besi/beton. Penghantar yang digunakan adalah Penghantar aluminiun campuran (All 
Aluminium Alloy Conductor = AAAC). Penghantar AAAC adalah penghantar untuk saluran udara Tegangan Rendah (TR) maupun Tegangan Menengah (TM), penghantar diregangkan pada isolator diantara tiang-tiang. Penghantar AAAC terbuat dari kawat-kawat aluminium campuran yang dipilin bulat, tidak berisolasi dan tidak berinti.

Selain memenuhi kelayakan teknis Penghantar AAAC juga ekonomis dari sisi pilihan harga, karena penggunaan Penghantar berbahan tembaga belum memungkinkan akibat tingginya harga tembaga dunia.

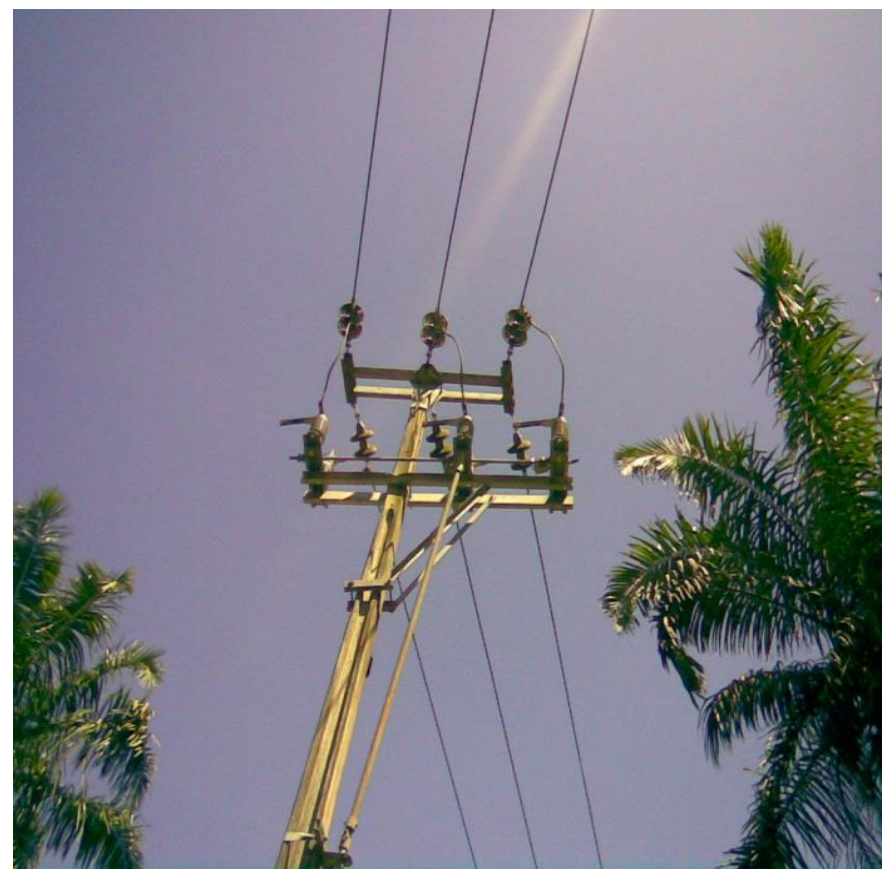

Gambar 1. Konstruksi SUTM

\section{METODE}

Metoda penelitian yang digunakan adalah metode observasi dan pengukuran di lapangan. Metode observasi menggunakan teori standar yang baku dalam hal ini adalah Standar-PLN dalam Buku Standar Perusahaan Umum Listrik Negara SPLN Hantaran Aluminium (AAC)[1], Buku1 Kriteria Disain Enjenering Kontruksi Jaringan Distribusi Tenaga Listrik PT PLN (Persero) Tahun 2010 [4] dan Buku5 Standar Konstruksi, Standar Konstruksi Jaringan Tegangan Menengah Tenaga Listrik. PT PLN (Persero) Tahun 2010 [5]. Sedangkan metode pengukuran digunakan dengan melihat kondisi implementasi di lapangan. Hasil dari kedua metode ini akan dibandingkan sehingga ratio antara teori dan implementasi di lapangan dapat diketahui, sehingga kelayakan proyek listrik dapat ditentukan.

\section{Peta Lokasi}

Peta Lokasi adalah lokasi tempat penelitian ini diadakan yaitu lokasi Penyulang Merbau di Daerah Ma.Tembesi Kab.Batanghari - Jambi.

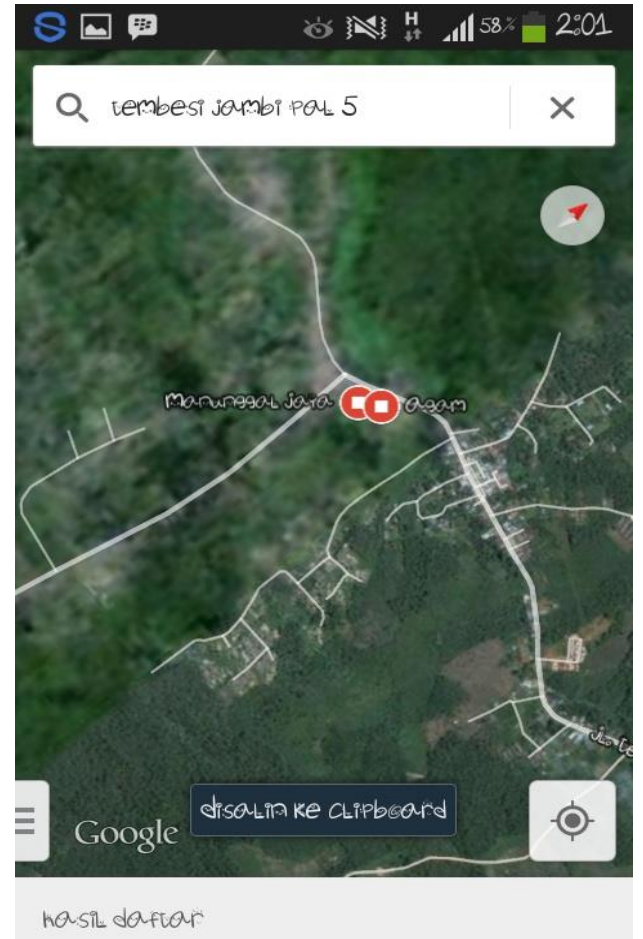

Gambar 2. Peta lokasi JTM Penyulang Merbau

\section{Peta Tiang}

Peta tiang adalah skema gambar titik tiang dalam analisis jaringan tegangan menengah ini yang bertujuaan agar dapat mengetahui jenis tiang, jumlah tiang dan pemilihan pada pemakaian jenis tiang.

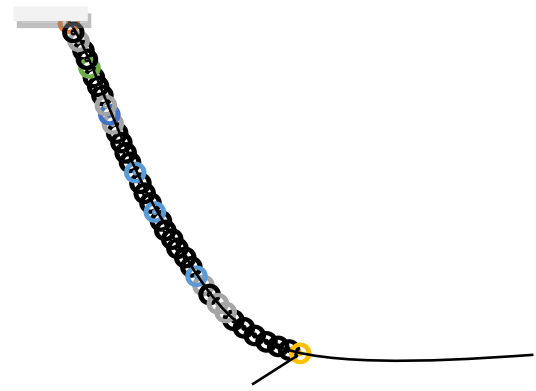

Gambar 3. Lokasi Tiang sesuai Peta Lokasi No. 1-39

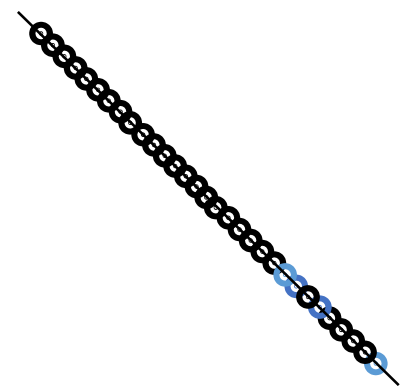

Gambar 4. Lokasi Tiang sesuai Peta Lokasi No. 40-70

\section{HASIL DAN PEMBAHASAN Menentukan Tiang \\ Lokasi}

Titik kordinat adalah titik peletakan tempat tiang diletakkan dengan menggunakan menggunakan GPS dengan aplikasi Maverick 
Jenis konstruksi

Jenis konstruksi tiang ditentukan berdasarkan penempatan tiang, sudut tiang, kondisi tanah sehingga dihasilkan daya dukung tanah sesuai dengan standar yang telah ditetapkan oleh PT.PLN dalam Sumber Buku 5 Standar Konstruksi JTM Tenaga Listrik [5]

\section{Kondisi tanah \& Daya dukung}

Perhitungan kontruksi sipil digunakan untuk pondasi pada semua tiang, baik tiang tumpu, tiang awal/akhir atau tiang sudut. Jenis dari konstruksi pondasi disesuaikan dengankondisi tanah dimana tiang tersebut akan didirikan.

Tabel 1. Klasifikasi kondisi tanah \& daya dukung

\begin{tabular}{|c|c|c|c|c|}
\hline $\begin{array}{l}\text { Kelas } \\
\text { Tanah }\end{array}$ & Tipe Tanah & Kondisi Tanah & $\begin{array}{c}\text { Max daya } \\
\text { dukung Tanah }\end{array}$ & $\begin{array}{c}\text { Parameter }(\mathrm{C}) \& \\
\text { sudut gesek } \Phi^{0}\end{array}$ \\
\hline 1 & Cohesive Granular & Sangat lunak tanpa Pasir & $1000 \mathrm{daN} / \mathrm{m} 2$ & $\begin{array}{l}\mathrm{C}: 1500-2500 \mathrm{daN} / \mathrm{m} 2 \\
\Phi: 250-300\end{array}$ \\
\hline 2 & Cohesive Granular & $\begin{array}{l}\text { Tanah lunak, endapan lumpur } \\
\text { sedikit pasir }\end{array}$ & $2500-7500 \mathrm{daN} / \mathrm{m} 2$ & $\begin{array}{l}\mathrm{C}: 2500-5000 \mathrm{daN} / \mathrm{m} 2 \\
\Phi: 300-350\end{array}$ \\
\hline 3 & Cohesive Granular & $\begin{array}{l}\text { Tanah keras berpasir coarsif berpasir } \\
\text { gravel (tanah liat) }\end{array}$ & $7500-1500 \mathrm{daN} / \mathrm{m} 2$ & $\begin{array}{l}\mathrm{C}: 5000-8000 \mathrm{daN} / \mathrm{m} 2 \\
\Phi: 350-400\end{array}$ \\
\hline 4 & Cohesive Granular & Lumpur keras, endapan keras & $15.000-30.000 \mathrm{daN} / \mathrm{m} 2$ & $\begin{array}{l}\mathrm{C}: 8000-11000 \mathrm{daN} / \mathrm{m} 2 \\
\Phi: 400-450\end{array}$ \\
\hline 5 & Cohesive Granular & $\begin{array}{l}\text { Lumpur sangat keras, tanah liat } \\
\text { keras berpasir }\end{array}$ & $30.000-60.000 \mathrm{daN} / \mathrm{m} 2$ & $\begin{array}{l}C: 11000-14000 \mathrm{daN} / \mathrm{m} 2 \\
\Phi: 450-500\end{array}$ \\
\hline 6 & Rock & Batu cadas & $3.000 \mathrm{daN} / \mathrm{m} 2$ & $\begin{array}{l}\mathrm{C}: 20000-28000 \mathrm{daN} / \mathrm{m} 2 \\
\Phi: 900-1000\end{array}$ \\
\hline
\end{tabular}

Sumber: CAC proyek kelistrikan RE-II PT PLN (Persero)

Dari hasil perhitungan tentang lokasi (titik kordinat) dan dari hasil survey didapat bahwa jenis tanah di lokasi tiang adalah Cohesive Granular: tanah liat. Dari hasil hitung dan survey maka jenis konstruksi tiang yang memungkinkan untuk digunakan adalah sebagaimana tabel dibawah ini:
Tabel 2. Jenis konstruksi tiang

\begin{tabular}{|c|c|c|c|}
\hline No & Tipe & Jenis & Keterangan \\
\hline 1 & & TM 1 & $\begin{array}{l}\text { Penempatan untuk jaringan lurus } \\
\text { atau } 0^{0}-5^{0}\end{array}$ \\
\hline 2 & & TM 3 & Penarikan pada sudut $15^{0}-30^{\circ}$ \\
\hline 3 & & TM 5 & Stopan pada jaringan lurus \\
\hline 4 & & TM 8 & $\begin{array}{l}\text { Percabangan pada simpang tiga } \\
\text { (pertigaan) }\end{array}$ \\
\hline 5 & & TM 10 & Penarikan pada sudut $60^{\circ}-90^{\circ}$ \\
\hline 6 & & TM 11 & Tiang awal dari gardu induk \\
\hline 7 & & TM 1 & $\begin{array}{l}\text { Jaringan lurus atau } 0^{0}-5^{0} \text { dengan } \\
\text { tiang } 9 \mathrm{~m}\end{array}$ \\
\hline \multicolumn{4}{|c|}{ Jumlah } \\
\hline
\end{tabular}

Tabel 3. Titik Koordinat Tiang

\begin{tabular}{|c|c|c|c|c|c|}
\hline No Tiang & Jenis Tiang & Titik Koordinat & No Tiang & Jenis Tiang & Titik Koordinat \\
\hline 1 & TM 1 & 43.608,E10 & 36 & TM 1 & $43.323, \mathrm{BT}$ \\
\hline 2 & TM 1 & 43.576, BT & 37 & TM 1 & $43.333, \mathrm{BT}$ \\
\hline 3 & TM 3 & $43.549, \mathrm{BT}$ & 38 & TM 1 & $43.343, \mathrm{BS}$ \\
\hline 4 & TM 1 & $43.525, \mathrm{BT}$ & 39 & TM 8 & $43.359, \mathrm{BS}$ \\
\hline 5 & TM 1 & 43.497, BT & 40 & TM 1 & 43.384, BS \\
\hline 6 & TM 0 & 43.432, BT & 41 & TM 1 & $43.417, \mathrm{BS}$ \\
\hline 7 & TM 1 & 43.446, BT & 42 & TM 1 & $43.442, \mathrm{BS}$ \\
\hline 8 & TM 1 & 43.459, BT & 43 & TM 1 & $43.469, \mathrm{BS}$ \\
\hline 9 & TM 1 & $43.474, \mathrm{BT}$ & 44 & TM 1 & $43.501, \mathrm{BS}$ \\
\hline 10 & TM 3 & 43.486, BT & 45 & TM 1 & $43.528, \mathrm{BS}$ \\
\hline 11 & TM 5 & 43.489, BT & 46 & TM 1 & $43.554, \mathrm{BS}$ \\
\hline 12 & TM 3 & 43.484, BT & 47 & TM 1 & 43.586, BS \\
\hline 13 & TM 1 & $43.463, \mathrm{BT}$ & 48 & TM 1 & 43.611, BS \\
\hline 14 & TM 1 & $43.450, \mathrm{BT}$ & 49 & TM 1 & $43.640, \mathrm{BS}$ \\
\hline 15 & TM 1 & 43.433, BT & 50 & TM 1 & 43.665, BS \\
\hline 16 & TM 1 & $43.420, \mathrm{BT}$ & 51 & TM 1 & 43.694, BS \\
\hline 17 & TM 5 & $43.403, \mathrm{BS}$ & 52 & TM 1 & $43.720, \mathrm{BS}$ \\
\hline 18 & TM 1 & 43.387, BT & 53 & TM 1 & $43.750, \mathrm{BS}$ \\
\hline 19 & TM 1 & $43.370, \mathrm{BT}$ & 54 & TM 1 & $43.778, \mathrm{BS}$ \\
\hline 20 & TM 1 & 43.361, BS & 55 & TM 1 & 43.804, BS \\
\hline
\end{tabular}




\begin{tabular}{|c|c|c|c|c|c|}
\hline 21 & TM 5 & $43.356, \mathrm{BS}$ & 56 & TM 1 & $43.833, \mathrm{BS}$ \\
\hline 22 & TM 1 & $43.350, \mathrm{BT}$ & 57 & TM 1 & $43.859, \mathrm{BS}$ \\
\hline 23 & TM 1 & $43.344, \mathrm{BS}$ & 58 & TM 1 & $43.888, \mathrm{BS}$ \\
\hline 24 & TM 1 & $43.338, \mathrm{BS}$ & 59 & TM 1 & $43.915, \mathrm{BS}$ \\
\hline 25 & TM 1 & $43.332, \mathrm{BS}$ & 60 & TM 1 & 43.941, BS \\
\hline 26 & TM 1 & 43.326, BT & 61 & TM 1 & $43.969, \mathrm{BS}$ \\
\hline 27 & TM 1 & $43.320, \mathrm{BS}$ & 62 & TM 5 & $44.000, \mathrm{BS}$ \\
\hline 28 & TM 5 & $43.315, \mathrm{BS}$ & 63 & TM 1 & $44.030, \mathrm{BS}$ \\
\hline 29 & TM 3 & 43.307, BT & 64 & TM 1 & $44.057, \mathrm{BS}$ \\
\hline 30 & TM 1 & $43.298, \mathrm{BS}$ & 65 & TM 1 & $44.085, \mathrm{BS}$ \\
\hline 31 & TM 3 & $43.287, \mathrm{BS}$ & 66 & TM 1 & $44.114, \mathrm{BS}$ \\
\hline 32 & TM 3 & $43.283, \mathrm{BS}$ & 67 & TM 1 & $44.142, \mathrm{BS}$ \\
\hline 33 & TM 1 & $43.290, \mathrm{BT}$ & 68 & TM 1 & $44.169, \mathrm{BS}$ \\
\hline 34 & TM 1 & $43.301, \mathrm{BT}$ & 69 & TM 1 & $44.199, \mathrm{BS}$ \\
\hline 35 & TM 1 & 43.312, BT & 70 & TM 5 & 44.227, BS \\
\hline
\end{tabular}

Hasil perhitungan menunjukkan bahwa jumlah tiang yang digunakan berjumlah 70 buah dengan konstruksi jenis tiang adalah TM1, TM3, TM5, TM10 dan TM11 dengan rincian sebagai berikut:

Tabel 4. Jumlah \& jenis konstruksi tiang

\begin{tabular}{ccc}
\hline No & Jenis Tiang & Jumlah Tiang (bh) \\
\hline 1 & TM 1 & 55 \\
2 & TM 3 & 6 \\
3 & TM 5 & 6 \\
4 & TM 8 & 1 \\
5 & TM 10 & 1 \\
6 & TM 11 & 1 \\
Jumlah & & 70 \\
\hline
\end{tabular}

\section{Panjang dan diameter Tiang}

Panjang dan diameter tiang ditentukan berdasarkan beban kerja tiang sebagaimana yang ditentukan dalam S-PLN [5].

Tabel 5. Panjang, diameter dan batas tanam tiang [5]

\begin{tabular}{cccc}
\hline $\begin{array}{c}\text { Panjang } \\
(\mathbf{m})\end{array}$ & $\begin{array}{c}\text { Batastanam } \\
(\mathbf{m})\end{array}$ & $\begin{array}{c}\text { Diameter } \\
(\mathbf{c m})\end{array}$ & $\begin{array}{c}\text { Beban kerja } \\
(\mathbf{d a N})\end{array}$ \\
\hline 9 & 1,5 & 15,7 & 100 \\
11 & 1,9 & 15,7 & 200 \\
12 & 2,0 & 19 & $\mathbf{2 0 0}$ \\
\hline
\end{tabular}

Hasil perhitungan dan hasil survey beban kerja tanah liat (Cohesive Granular) menunjukkan bahwa daya dukung tanah maksimum sebesar 7500-1500 daN/m2 sehingga pemakaian tiang dengan beban kerja sebesar 200 daN sangat memungkinkan. Perlu diketahui bahwa pabrikasi pembuatan tiang hanya memproduksi tiang dengan beban kerja 100 daN dan 200 daN.

Berdasarkan tabel diatas maka panjang tiang yang memenuhi standar untuk dipergunakan adalah tiang dengan panjang $9 \mathrm{~m}$ dan $12 \mathrm{~m}$ dengan beban kerja 200 daN.

\section{Guy Wire $(G W)$ \& Horizontal Guy Wire (HGW)}

Sebelum penarikan penghantar, pasang $\mathrm{GW}$ atau tiang topang tarik pada tiang awal, tiang akhir atau tiang sudut sesuai rancangan kontruksi SUTM pada trase bersangkutan. GW (topang tarik) diberikan jika beban mekanis melebihi working load tiang itu sendiri. Posisi GW terletak pada belakang tiang dengan 1 penyangga dengan panjang maksimal $15 \mathrm{~m}$. GW diperlukan setiap tiang dalam penarikan pada sudut $15^{\circ}-30^{\circ}$.

HGW diberikan jika beban mekanis melebihi working load tiang itu sendiri. Posisi HGW terletak pada seberang jalan diatas tiang dengan 1 penyangga dengan panjang maksimal $15 \mathrm{~m}$. Panjang HGW tergantung pada lebar padan jalan.

Dari hasil survey dan perhitungan diatas maka diperlukan:

$\begin{array}{ll}\mathrm{HGW} & =2 \mathrm{buah} \\ \mathrm{GW} & =6 \mathrm{buah} \\ \text { Konektor (Joint slave) } & =19 \mathrm{buah} \\ \text { Plat } & =70 \mathrm{buah}\end{array}$

Berdasarkan standarisasi PLN [4] jumlah Konektor serta Plat adalah jumlah diatas

\section{Menentukan Penghantar}

Jarak antar penghantar harus memperhitungkan pertimbangan yaitu:

a. Pengaruh elektris akibat hubung singkat,

b. Kemungkinan persinggungan antar 2 penghantar.

Rumus empiris untuk jarak antar penghantar:

$$
\begin{aligned}
& D=0,75 \sqrt{S}+\frac{V^{2}}{20000} \quad[1] \\
& D=\sqrt{S}+\frac{V}{150}
\end{aligned}
$$

Dimana:

$$
\begin{array}{ll}
\mathrm{S} & =\text { Tinggi Andongan }(\mathrm{Sag}) \\
\mathrm{V} & =\text { Tegangan Kerja }(\mathrm{kV})
\end{array}
$$
adalah:

Panjang palang (Cross-Arm) yang diperlukan

$\mathrm{L}=2 \times$ jarak antar penghantar $+2 \times$ jarak antara titik luar lubang pin isolatordengan ujung Palang $( \pm 10$ $\mathrm{cm}$ ) Andongan ( $\mathrm{sag}$ ) adalah jarak antara garis lurus horizontal dengan titik terendah penghantar. Berat penghantar dihitung berdasarkan panjang penghantar 
sebenarnya sebagai fungsi dari jarak andongan dihitung dengan rumus sebagai berikut :

$L=a+\frac{8 s^{2}}{3 a}$

Dimana:

$\mathrm{L} \quad=$ Panjang total penghantar $(\mathrm{m})$

$a \quad=$ Jarak gawang $(\mathrm{m})$

$\mathrm{s} \quad=$ Panjang andongan $(\mathrm{m})$

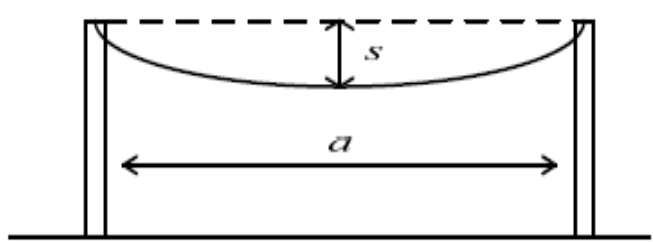

Gambar 5. Jarak Gawang dan Andongan

Hasil perhitungan menunjukkan bahwa jarak antar andongan sepanjang $3675 \mathrm{~m}$ dengan rincian jarak antar gawang sebagai berikut :

Tabel 6. Panjang penghantar AAAC

\begin{tabular}{|c|c|c|c|c|c|c|c|}
\hline & Jenis Tiang & $\begin{array}{c}\text { Jarak } \\
\text { Gawang (m) }\end{array}$ & $\begin{array}{c}\text { Andongan } \\
\text { (m) }\end{array}$ & & Jenis Tiang & $\begin{array}{c}\text { Jarak } \\
\text { Gawang (m) }\end{array}$ & $\begin{array}{c}\text { Andongan } \\
\text { (m) }\end{array}$ \\
\hline & & & & & kabel & & 1.814 \\
\hline $1-2$ & TM 11 & 45 & 49 & $37-38$ & TM 1 & 45 & 49 \\
\hline $2-3$ & TM 1 & 45 & 49 & $38-39$ & TM 1 & 45 & 49 \\
\hline $3-4$ & TM 3 & 45 & 49 & $39-40$ & TM 1 & 50 & 54 \\
\hline $4-5$ & TM 1 & 45 & 49 & $40-41$ & TM 8 & 50 & 54 \\
\hline $5-6$ & TM 1 & 48 & 53 & $41-42$ & TM 1 & 50 & 54 \\
\hline $6-7$ & TM 10 & 45 & 49 & $42-43$ & TM 1 & 45 & 49 \\
\hline $7-8$ & TM 1 & 48 & 54 & $43-44$ & TM 1 & 45 & 49 \\
\hline $8-9$ & TM 1 & 50 & 54 & $44-45$ & TM 1 & 45 & 49 \\
\hline $9-10$ & TM 1 & 48 & 53 & $45-46$ & TM 1 & 45 & 49 \\
\hline $10-11$ & TM 3 & 49 & 54 & $46-47$ & TM 1 & 45 & 49 \\
\hline $11-12$ & TM 5 & 45 & 49 & $47-48$ & TM 1 & 48 & 52 \\
\hline $12-13$ & TM 3 & 45 & 54 & $48-49$ & TM 1 & 48 & 52 \\
\hline $13-14$ & TM 1 & 50 & 54 & $49-50$ & TM 1 & 50 & 54 \\
\hline $14-15$ & TM 1 & 50 & 54 & $50-51$ & TM 1 & 50 & 54 \\
\hline $15-16$ & TM 1 & 50 & 54 & $51-52$ & TM 1 & 50 & 54 \\
\hline $16-17$ & TM 1 & 48 & 53 & $52-53$ & TM 1 & 48 & 53 \\
\hline $17-18$ & TM 5 & 45 & 49 & $53-54$ & TM 1 & 50 & 54 \\
\hline $18-19$ & TM 1 & 48 & 53 & $54-55$ & TM 1 & 50 & 54 \\
\hline $19-20$ & TM 1 & 45 & 49 & $55-56$ & TM 1 & 50 & 54 \\
\hline $20-21$ & TM 1 & 45 & 49 & $56-57$ & TM 1 & 45 & 49 \\
\hline $21-22$ & TM 5 & 48 & 53 & $57-58$ & TM 1 & 48 & 53 \\
\hline $22-23$ & TM 1 & 50 & 54 & $58-59$ & TM 1 & 48 & 53 \\
\hline $23-24$ & TM 1 & 50 & 54 & $59-60$ & TM 1 & 49 & 54 \\
\hline $24-25$ & TM 1 & 50 & 54 & $60-61$ & TM 1 & 50 & 54 \\
\hline $25-26$ & TM 1 & 50 & 54 & $61-62$ & TM 1 & 48 & 53 \\
\hline $26-27$ & TM 1 & 50 & 54 & $62-63$ & TM 1 & 48 & 53 \\
\hline $27-28$ & TM 1 & 50 & 54 & $63-64$ & TM 5 & 46 & 51 \\
\hline $28-29$ & TM 5 & 50 & 54 & $64-65$ & TM 1 & 45 & 49 \\
\hline $29-30$ & TM 3 & 50 & 54 & $65-66$ & TM 1 & 45 & 49 \\
\hline $30-31$ & TM 1 & 45 & 49 & $66-67$ & TM 1 & 45 & 49 \\
\hline $31-32$ & TM 3 & 48 & 53 & $67-68$ & TM 1 & 48 & 53 \\
\hline $32-33$ & TM 3 & 45 & 49 & $68-69$ & TM 1 & 45 & 49 \\
\hline $33-34$ & TM 1 & 45 & 49 & $69-70$ & TM 1 & 45 & 49 \\
\hline $34-35$ & TM 1 & 45 & 49 & $70-71$ & TM 1 & 45 & 49 \\
\hline \multirow[t]{2}{*}{$35-36$} & TM 1 & 45 & 49 & $71-72$ & TM 5 & 50 & 54 \\
\hline & Total & & & & 3675 & & \\
\hline
\end{tabular}

Dari hasil tersebut maka panjang Penghantar (R, S dan T) yang diperlukan adalah $3675 \times 3=11.025 \mathrm{~m}$ dengan konduktivitas penghantar : $\mathrm{Cu}=56$ dan Aluminium $=32,7$
Berdasarkan standarisasi PLN [4] jumlah Isolator ditentukan berdasarkan jenis tiang sebagaimana tabel dibawah ini:

\section{Menentukan Isolator}


Tabel 7. Jumlah Isolator Tumpu sesuai jenis tiang [4]

\begin{tabular}{ccc} 
No Tiang & Jenis Tiang & Jumlah IsolatorTumpu/tiang \\
\hline 1 & TM 1 & 3 \\
2 & TM 3 & 6 \\
3 & TM 5 & 6 \\
4 & TM 8 & 7 \\
5 & TM 10 & 6 \\
6 & TM 11 & 3 \\
Jumlah & Jumlah & \\
\hline
\end{tabular}

Tabel 8. Jumlah Isolator Tarik sesuai jenis tiang [4]

\begin{tabular}{ccc}
\hline No Tiang & Jenis Tiang & Jumlah Isolator Tarik/tiang \\
\hline 1 & TM 1 & 0 \\
2 & TM 3 & 0 \\
3 & TM 5 & 6 \\
4 & TM 8 & 0 \\
5 & TM 10 & 0 \\
6 & TM 11 & 3 \\
Jumlah & & \\
\hline
\end{tabular}

Dari hasil ketetapan diatas maka jumlah Isolator Tumpu yang diperlukan adalah sebanyak 253 bh dengan perincian sebagai berikut :

Tabel 9. Jumlah Isolator Tumpu

\begin{tabular}{ccccc}
\hline $\begin{array}{c}\text { No } \\
\text { Tiang }\end{array}$ & $\begin{array}{c}\text { Jenis } \\
\text { Tiang }\end{array}$ & $\begin{array}{c}\text { Jumlah } \\
\text { Isolator } \\
\text { Tumpu/tiang }\end{array}$ & $\begin{array}{c}\text { Jumlah } \\
\text { Tiang } \\
\text { (bh) }\end{array}$ & $\begin{array}{c}\text { Jumlah } \\
\text { Isolator } \\
\text { Tumpu }\end{array}$ \\
\hline 1 & TM 1 & 3 & 55 & 165 \\
2 & TM 3 & 6 & 6 & 36 \\
3 & TM 5 & 6 & 6 & 36 \\
4 & TM 8 & 7 & 1 & 7 \\
5 & TM 10 & 6 & 1 & 6 \\
6 & TM 11 & 3 & 1 & 3 \\
& Jumlah & & 70 & 253 \\
\hline
\end{tabular}

Sedangkan jumlah Isolator Tarik yang diperlukan adalah sebanyak 39 bh dengan perincian sebagai berikut :

Tabel 9 : Jumlah Isolator Tarik

\begin{tabular}{ccccc}
\hline $\begin{array}{c}\text { No } \\
\text { Tiang }\end{array}$ & $\begin{array}{c}\text { Jenis } \\
\text { Tiang }\end{array}$ & $\begin{array}{c}\text { Jumlah } \\
\text { Isolator } \\
\text { Tarik/tiang }\end{array}$ & $\begin{array}{c}\text { Jumlah } \\
\text { Tiang } \\
\text { (bh) }\end{array}$ & $\begin{array}{c}\text { Jumlah } \\
\text { Isolator } \\
\text { Tarik }\end{array}$ \\
\hline 1 & TM 1 & 0 & 55 & 0 \\
2 & TM 3 & 0 & 6 & 0 \\
3 & TM 5 & 6 & 6 & 36 \\
4 & TM 8 & 0 & 1 & 0 \\
5 & TM 10 & 0 & 1 & 0 \\
6 & TM 11 & 3 & 1 & 3 \\
Jumlah & & & 70 & 39 \\
\hline
\end{tabular}
jumlah :

Perhitungan jumlah isolator menunjukkan bahwa Isolator Tumpu $=253$ buah

Isolator Tarik $=39$ buah

\section{Menentukan Transformator}

Trafo dari Gardu Induk menggunakan transformator yang sudah tersedia (eksisting) dengan kapasitas $100 \mathrm{kVA}$ tegangan 380 volt berjumlah 1 unit.

\section{Hasil Hitung dan Realisasi}

Hasil Hitung dibandingkan dengan hasil Realisasi pemakaian Konduktor AAAC $70 \mathrm{~mm}^{2}$ sebesar 107,2\% $(+)$, Tiang beton $12 \mathrm{~m}$ sebesar $98,6 \%(-)$, Tiang beton $9 \mathrm{~m}$ sebesar $200 \%$ (+) dan untuk komponen lainnya tertera dalam tabel dibawah ini.

Tabel 10. Rasio Hasil Hitung dan Realisasi Komponen

\begin{tabular}{|c|c|c|c|c|}
\hline URAIAN & Sat & $\begin{array}{l}\text { Real } \\
\text { isasi }\end{array}$ & $\begin{array}{l}\text { Hasil } \\
\text { Hitung }\end{array}$ & $+/-$ \\
\hline $\begin{array}{l}\text { Penghantar kabel } \\
\text { AAAC } 70 \mathrm{~mm}^{2}\end{array}$ & $\mathrm{mtr}$ & 11.825 & 11.025 & $107,2 \%(+)$ \\
\hline $\begin{array}{l}\text { Tiang Beton } 12 \\
\text { meter, } 200 \mathrm{daN}\end{array}$ & bh & 68 & 69 & $98,6 \%(-)$ \\
\hline $\begin{array}{l}\text { Tiang Beton } 9 \\
\text { meter, } 200 \mathrm{daN}\end{array}$ & bh & 2 & 1 & $200 \%(+)$ \\
\hline Transfor dari GI & unit & 1 & 1 & eksisting \\
\hline Trafo Distribusi & unit & 1 & 1 & eksisting \\
\hline TM-1 & Set & 55 & 55 & $100 \%$ \\
\hline TM-3 & Set & 6 & 6 & $100 \%$ \\
\hline TM-5 & Set & 6 & 6 & $100 \%$ \\
\hline TM-8 & Set & 1 & 1 & $100 \%$ \\
\hline TM-10 & Set & 1 & 1 & $100 \%$ \\
\hline TM-11 & Set & 1 & 1 & $100 \%$ \\
\hline $\begin{array}{ll}\text { Isolator } & \text { Tarik } \\
\mathrm{kV}\end{array}$ & Set & 47 & 39 & $120,5 \%(+)$ \\
\hline $\begin{array}{l}\text { Isolator Tumpu } 20 \\
\mathrm{kV}\end{array}$ & set & 269 & 253 & $106,3 \%(+)$ \\
\hline Guy Wire (GW) & Set & 4 & 6 & $66,6 \%(-)$ \\
\hline HGW & Set & 3 & 2 & $150 \%(+)$ \\
\hline Joint Slave $70 \mathrm{~mm}$ & Set & 19 & 19 & $100 \%$ \\
\hline Plat Tanda Bahaya & Set & 70 & 70 & $100 \%$ \\
\hline
\end{tabular}

\section{SIMPULAN}

a. Hasil Hitung dibandingkan dengan hasil Realisasi pemakaian komponen di lapangan untuk pemakaian kabel penghantar hampir mendekati, selisih hanya berkisar 7,2\% (+) tetapi pemakaian tiang walaupun jumlahnya sama 70 bh tetapi ada perbedaan jumlah dalam penggunaan tiang $12 \mathrm{~m}$ dan $9 \mathrm{~m}$ (lihat table). Pemakaian tiang dengan panjang tertentu bagi pelaksana proyek seharusnya mereferensi Standar PLN walaupun beban kerja tiang masih terpenuhi $(200 \mathrm{daN})$.

b. Dengan selalu diadakannya evaluasi di setiap proyek maka data ini dapat digunakan sebagai masukan bagi pemilik maupun pelaksana proyek, agar kualitas dan keandalan sistem dapat terpenuhi

\section{DAFTAR PUSTAKA}

[1] Arfita Yuana Dewi Rachman, fauzan, Perencanaan Saluran Udara Tegangan Menengah (SUTM) 20 KV Pada Komplek Perkebunan AMP (Agra Masang Perkasa) Lubuk Basung, Jurnal teknik elektro ITP volume 1 No.2, 2012

[2] Andang Purnomo Putro, Kartono, Perluasan Jaringan Tegangan Menengah Tiga Phasa di PT. Saniharto Semarang Jurnal Desiminasi Teknologi, Volume 1, Nomor 1, Semarang, 2013 
[3] Buku Standar Perusahaan Umum Listrik Negara SPLN, Hantaran Aluminium (AAC). PT.PLN (Persero). Jakarta, Jakarta, 1981

[4] Buku1 Kriteria Disain Enjenering Kontruksi Jaringan Distribusi Tenaga Listrik PT PLN (Persero), Jakarta, 2010

[5] Buku5 Standar Konstruksi, Standar Konstruksi Jaringan Tegangan Menengah Tenaga Listrik. PT PLN (Persero), Jakarta, 2010 